\title{
Study of the dependence of equilibrium sorption humidity of heat-insulating products on temperature
}

\author{
Artem Petrov 1*[0000-0001-6643-9110], and Valerij Kupriyanov 1[0000-0002-9862-4326] \\ ${ }^{1}$ Kazan State University of Architecture and Engineering, 420043, Zelenaya st., Kazan, Russia
}

\begin{abstract}
The desiccator method for products like mineral wool has a low accuracy, which is due to the small mass of the samples and the uneven content of the binder between the samples. The standard method does not involve testing materials at different temperatures. However, the value of sorption moisture depends not only on the nature and structure of the material, but also on the temperature conditions. At the moment, the regularities of changes in the sorption moisture content of materials depending on the air temperature have been studied only in separate scientific works and do not cover the entire spectrum of modern building materials. The paper presents the results of a study of the sorption moisture content of modern mineral wool products at various temperatures above 0 ${ }^{\circ} \mathrm{C}$. The results show an increase in sorption humidity with decreasing temperature from $22{ }^{\circ} \mathrm{C}$ to $0{ }^{\circ} \mathrm{C}$. The greatest increase in humidity occurs at values of relative air humidity in the range of 90-97\%. It is shown that the standard desiccator method for studying sorption moisture requires scientific development and increased control of test conditions with decreasing temperature.
\end{abstract}

Keywords: sorption isotherm, insulation, mineral wool, temperature conditions, test method.

\section{Introduction}

In thermal calculations, the moisture content of materials plays a significant role in heat transfer. The thermal conductivity of the material will depend on the sorption moisture [15]. For this reason, the protective properties of the enclosing structures may decrease. A number of works are devoted to the study of the protective properties of enclosing structures, taking into account solar radiation and electromagnetic radiation [6-11]. Experimental sorption isotherms make it possible to determine the moistening of structural materials with sorption moisture, and can also be used to study the porous structure of materials [12]. These characteristics are successfully used to predict the properties of materials of enclosing structures during operation [13-19]. Obtaining experimental sorption isotherms at the current moment is associated with a number of ambiguities. The standard technique for measuring the sorption moisture content of materials is based on GOST

* Corresponding author: ruarty@mail.ru 
24816 (Building materials. Method of equilibrium hygroscopic moisture determination). According to this technique, the sorption moisture is measured by the desiccator method at a constant temperature of $20^{\circ} \mathrm{C}$. The desiccator method for products like mineral wool has a low accuracy, which is due to the small mass of the samples and the uneven content of the binder between the samples [12]. The standard method does not involve testing materials at different temperatures. However, the value of sorption moisture depends not only on the nature and structure of the material, but also on the air temperature. At the moment, the regularities of changes in the sorption moisture content of materials depending on the air temperature have been studied only in separate scientific works [20-25] and do not cover the entire spectrum of modern building materials.

The paper presents the results of a study of the sorption moisture content of modern mineral wool products at various temperatures above $0{ }^{\circ} \mathrm{C}$.

\section{Materials and methods}

The study of sorption moisture was carried out for mineral wool products made of stone fiber of different density, table 1.

Table 1. Characteristics of the investigated materials

\begin{tabular}{|c|c|l|c|c|}
\hline № & $\begin{array}{c}\text { Density, } \\
\mathrm{kg} / \mathrm{m}^{3}\end{array}$ & Insulation plate brand & $\begin{array}{c}\text { Manufacturing technical } \\
\text { regulations }\end{array}$ & Manufacturer \\
\hline 1 & 35 & Light Batts Scandic & $5762-050-45757203-15$ & Ltd «Rockwool» \\
\hline 2 & 100 & Roof Batts N Combi & $5762-050-45757203-15$ & Ltd «Rockwool» \\
\hline 3 & 120 & Technofloor Standard & $5762-010-74182181-2012$ & «TECHNONICOL» \\
\hline 4 & 170 & BASWOOL Roof B & $5762-001-80015406-2010$ & Ltd «Baswool» \\
\hline
\end{tabular}

Compositions consisting of water-soluble synthetic resins, modifying, hydrophobizing, dedusting and other additives are used as a binder in the production of plates. The content of the organic binder based on phenol-formaldehyde resin is $4-4.5 \%$.

The test was carried out in accordance with GOST 24816, with the difference that the samples of materials were additionally tested at $20 \%$ relative humidity. Thus, the samples of materials were tested under 6 conditions of humidity $(20 \%, 40 \%, 60 \%, 80 \%, 90 \%, 97$ $\%$ ) at air temperature of $+0.5,+6$ and $+22{ }^{\circ} \mathrm{C}$. For each condition, 3 samples of the same density were tested. Before testing, each sample was dried in a drying oven at a temperature of $60^{\circ} \mathrm{C}$ until a constant weight was established. To create a certain relative humidity in the desiccators, an aqueous solution of sulfuric acid of various concentrations was used.

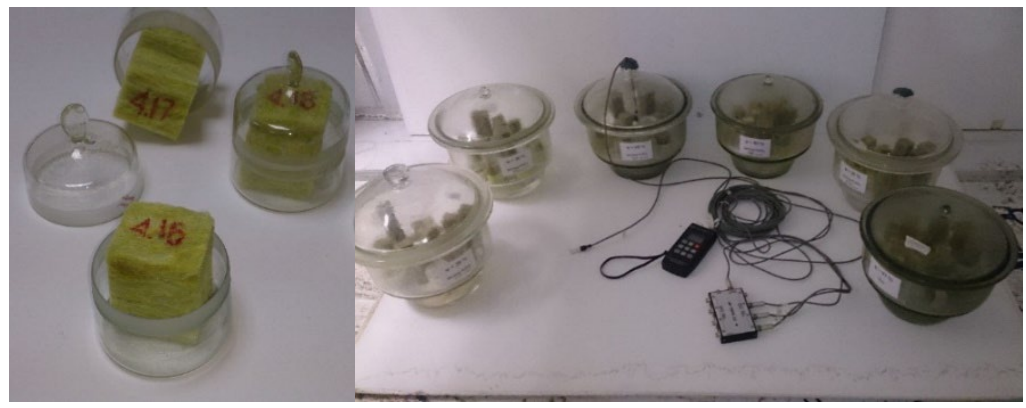

Fig. 1. General view of samples and test equipment used 
To maintain constant temperature conditions, the desiccators were placed in a thermostated chamber. Additionally, the temperature and relative humidity of the air were recorded by the measuring complex «Terem-3.2», the sensors of which (DTG-2.0) were fed through the hole in the desiccator lid, photographic recording, Fig. 1.

\section{Results and discussion}

After reaching the equilibrium sorption moisture content of mineral wool, the results were calculated as the arithmetic mean of the tests of three samples. The test results are presented in the form of material sorption isotherms for each density in Figure 2. It can be seen that as the temperature decreases from $22{ }^{\circ} \mathrm{C}$ to $0.6{ }^{\circ} \mathrm{C}$, the sorption moisture content of the materials tends to increase. In this case, the increase in sorption moisture mainly occurs in the range of relative humidity from $90 \%$ to $100 \%$. At humidity values below $90 \%$, the sorption moisture content of the materials practically did not change with decreasing temperature. An exception is the material of mineral wool with a density of $170 \mathrm{~kg} / \mathrm{m}^{3}$ produced by Ltd «Baswool», where an increase in sorption humidity with a decrease in temperature occurs in the entire range of the investigated air humidity.
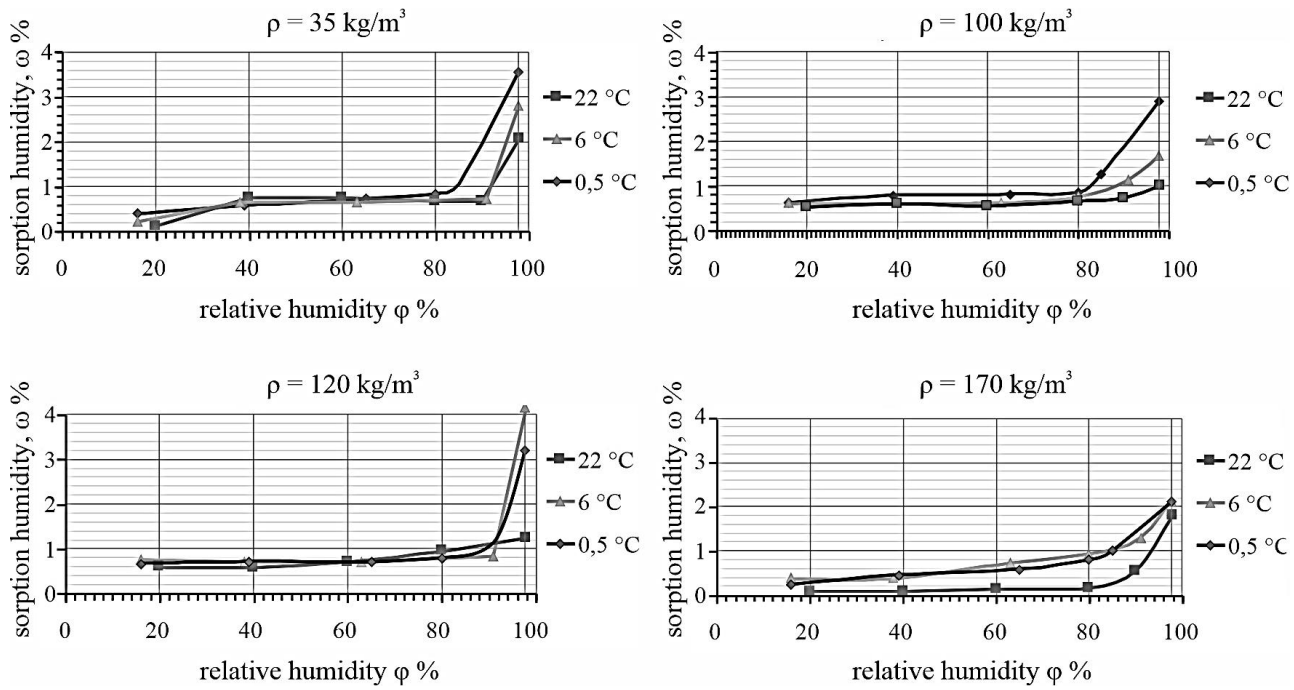

Fig. 2. Isotherms of sorption of mineral wool products from stone wool of different density at different temperatures.

It should be noted that insignificant changes in the sorption moisture content in the range below $90 \%$ can be associated with the limited accuracy of the desiccator method, the disadvantages of which are highlighted above. The regularities of changes in the sorption moisture content of a material with a density of $170 \mathrm{~kg} / \mathrm{m}^{3}$ from other investigated materials are most likely explained by the use of a different type of binder at the production stage. However, this assumption requires scientific research, where the sorption moisture should be determined separately for fiber and binder, as, for example, in [12]. So, according to article [12], the equilibrium moisture content of staple glass fiber without a binder is 0.0029 $\mathrm{kg} / \mathrm{kg}$, which is 66 times lower than these indicators for a phenol-formaldehyde binder $0.192 \mathrm{~kg} / \mathrm{kg}$ (data are given for a relative humidity of $80 \%$ ). The studied samples of mineral wool are treated with hydrophobizing additives, therefore, the sorption moisture content of the fibers themselves is ten times lower than the binder itself [12].

A significant increase in sorption humidity with a decrease in temperature for values of relative humidity of $97 \%$ can be associated with condensation processes as an additional 
mechanism of humidification. A slight change in the relative humidity from $97 \%$ upwards leads to a sharp increase in the sorption moisture content of the material. So, according to studies [26] in the range of relative humidity from $97.0 \%$ to $98.2 \%$, the sorption moisture content of mineral wool will be equal to $1.77 \%$ and $17.43 \%$, respectively. That is, an increase in the relative humidity in the desiccator by at least $1.2 \%$ can lead to a change in the result of the sorption humidity test by an order of magnitude. Such an accurate control of the relative humidity with a decrease in the air temperature in the desiccator method is problematic, in view of the small temperature fluctuations in the thermostated chamber and the uneven distribution of the relative air humidity throughout the desiccator volume. In this regard, the desiccator method for studying the sorption moisture content at different temperatures requires improvement.

\section{Conclusion}

Analysis of the obtained isotherms of sorption of mineral wool insulation of various brands suggests an increase in their moisture content when the temperature drops from $22{ }^{\circ} \mathrm{C}$ to 0 ${ }^{\circ} \mathrm{C}$. The greatest increase in humidity occurs at values of relative air humidity in the range of $90-97 \%$. It is shown that the standard desiccator method for studying sorption moisture requires scientific development and increased control of test conditions with decreasing temperature. Since even a slight increase in the relative humidity of air above $97 \%$ in the desiccator can change the percentage of sorption moisture content of the material by an order of magnitude.

\section{References}

1. Fayça El Fgaier, Zoubeir Lafhaj, Christophe Chapiseau, Emmanuel Antczak, Effect of sorption capacity on thermo-mechanical properties of unfired clay bricks, Journal of Building Engineering, 6, 86-92 (2016)

2. Xiaobo Zhang, Wolfgang Zillig, Hartwig M. Künzel, Christoph Mitterer, Xu Zhang, Combined effects of sorption hysteresis and its temperature dependency on wood materials and building enclosures - Part I: Measurements for model validation, Building and Environment, 106, 143-154 (2016) DOI: 10.1016/j.buildenv.2016.06.025

3. P. P. Pastushkov, N. V. Pavlenko, S. I. Gutnikov, D. Yu. Zheldakov, M. D. Stolyarov, Heat conductivity of aerogel-based rolled materials for high-thermal isolation for equipment and pipelines, IOP Conf. Ser.: Mater. Sci. Eng. 896, 012103

4. Yingying Wang, Zejiao Zhao, Yanfeng Liu, Dengjia Wang, Chao Ma, Jiaping Liu, Comprehensive correction of thermal conductivity of moist porous building materials with static moisture distribution and moisture transfer, Energy, 176, 103-118 (2019) DOI: $10.1016 /$ j.energy.2019.03.178

5. Maatouk Khoukhi, Ahmed Hassan, Salah Al Saadi, Shaimaa Abdelbaqi, A dynamic thermal response on thermal conductivity at different temperature and moisture levels of EPS insulation, Case Studies in Thermal Engineering, 14, 100481 (2019) DOI: 10.1016/j.csite.2019.100481

6. V. Kupriyanov and F. Sedova, in IOP Conf. Ser. Mater. Sci. Eng. (2020)

7. V. N. Kupriyanov and R. I. Shafigullin, in IOP Conf. Ser. Mater. Sci. Eng. (2018)

8. A. S. Petrov and V. N. Kupriyanov, in IOP Conf. Ser. Mater. Sci. Eng. (2018)

9. A. S. Petrov and V. N. Kupriyanov, Int. J. Pharm. Technol. 8, 11248 (2016)

10. V. N. Kupriyanov and R. I. Shafigullin, Izv. Vyss. Uchebnykh Zaved. Seriya Teknol. Tekst. Promyshlennosti 2016-Janua, 229 (2016) 
11. R. Kh. Mukhametrakhimov, R. I. Shafigullin, V. N. Kuprijanov, Izvestiya KGASU, 41, 224 (2017)

12. V. G. Gagarin, P. P. Pastushkov, Sorption of water vapour materials of mineral wool products of modern manufacture. Part II, Construction Materials, 6, 33-38 (2020) DOI 10.31659/0585-430X-2020-781-6-33-38

13. M. Maaroufi, F. Bennai, R. Belarbi, K. Abahri, Experimental and numerical highlighting of water vapor sorption hysteresis in the coupled heat and moisture transfers, Journal of Building Engineering, 40, 102321 (2021)

14. V. G. Gagarin, P. A. Khavanov, K. P. Zubarev, Steady-state and unsteady-state moisture regime of enclosing structure, IOP Conf. Ser.: Mater. Sci. Eng., 896, 012015 (2020) DOI 10.1088/1757-899X/896/1/012015

15. V. G. Gagarin, P. A. Khavanov, K. P. Zubarev, Moisture regime of enclosing structures with different thickness of insulation layer, IOP Conf. Ser.: Mater. Sci. Eng., 918 012113 (2020)

16. V. G. Gagarin, V. K. Akhmetov, K. P. Zubarev, Assessment of enclosing structure unsteady-state moisture behavior using moisture potential theory, IOP Conf. Ser.: Mater. Sci. Eng. 918, 012113 (2020) DOI 10.1088/1757-899X/918/1/012113

17. V. G. Gagarin, K. P. Zubarev, V. K. Akhmetov, The moisture regime calculation of single-layer enclosing structures on the basis of the discrete-continuum method application, IOP Conf. Ser.: Mater. Sci. Eng., 456012105 (2018) DOI 10.1088/1757899X/456/1/012105

18. M.Asli, F.Brachelet, E.Sassine, E.Antczak, Thermal and hygroscopic study of hemp concrete in real ambient conditions, Journal of Building Engineering, 28 April 2021, 102612, DOI: $10.1016 /$ j.jobe.2021.102612

19. Maatouk Khoukhi, The combined effect of heat and moisture transfer dependent thermal conductivity of polystyrene insulation material: Impact on building energy performance, Energy and Buildings, 169, 2018, 228-235, DOI: 10.1016/j.enbuild.2018.03.055.

20. G. Promis, L. Freitas Dutra, O. Douzane, A.D. Tran Le, T. Langlet, Temperaturedependent sorption models for mass transfer throughout bio-based building materials, Construction and Building Materials, 197, 2019, Pages 513-525

21. T. Colinart, P. Glouannec, Temperature dependence of sorption isotherm of hygroscopic building materials. Part 1: Experimental evidence and modeling, Energy and Buildings 139, 360-370 (2017) DOI: 10.1016/j.enbuild.2016.12.082

22. T. Colinart, P. Glouannec, Temperature dependence of sorption isotherm of hygroscopic building materials. Part 2: Influence on hygrothermal behavior of hemp concrete, Energy and Buildings 152, 42-51 (2017) DOI: 10.1016/j.enbuild.2017.07.016

23. Anh D. Tran Le, Driss Samri, Omar Douzane, Geoffrey Promis, Anh T. Nguyen, Thierry Langlet, Effect of Temperature Dependence of Sorption on Hygrothermal Performance of a Hemp Concrete Building Envelope, Encyclopedia of Renewable and Sustainable Materials, Elsevier, 2, 68-77 (2020)

24. G. Promis, L. Freitas Dutra, O. Douzane, A.D. Tran Le, T. Langlet, Temperaturedependent sorption models for mass transfer throughout bio-based building materials, Construction and Building Materials, 197, 513-525 (2019) DOI: 10.1016/j.conbuildmat.2018.11.212

25. Hsuan-Yu Chen, Chiachung Chen, Equilibrium relative humidity method used to determine the sorption isotherm of autoclaved aerated concrete, Building and Environment, 81, 427-435 (2014) DOI: 10.1016/j.buildenv.2014.07.021

26. Halina Garbalińska, Magdalena Bochenek, Winfried Malorny, Julia von Werder, Comparative analysis of the dynamic vapor sorption (DVS) technique and the traditional method for sorption isotherms determination - Exemplified at autoclaved 
aerated concrete samples of four density classes, Cement and Concrete Research, 91, 97-105 (2017) DOI: 10.1016/j.cemconres.2016.11.001 